\title{
Frankenstein e o espectro do desejo*
}

\author{
Richard Miskolci**
}

\section{Resumo}

A partir da polêmica sobre a autoria de Frankenstein (1818), ensaio uma análise que o insere em uma história cultural da subjetividade. Exemplar do gótico inicial, provável primeiro exemplar de ficção científica, o romance também faz parte de uma vertente literária que explora a experiência de ser "assombrado" por um fantasma, uma memória, um monstro. Busco reconstituir essa experiência em termos históricos e psicossociais para compreender as relações entre desejo, normas e convenções culturais na emergência da heterossexualidade compulsória.

Palavras-chave: Frankenstein, história da subjetividade, desejo homossocial masculino, heterossexualidade compulsória, medo, violência.

\footnotetext{
" Recebido para publicação em 17 de fevereiro de 2011, aceito em 10 de agosto de 2011. Este ensaio surgiu a partir de uma proposta de Mariza Corrêa e, durante sua criação, foi enriquecido pelo diálogo sempre instigante com Mariza e também com a psicanalista Márcia Arán, a quem dedico este texto in memoriam.

** Departamento de Sociologia da UFSCar, coordenador do Grupo de Pesquisa Corpo, Identidades e Subjetivações (www.ufscar.br/cis) e pesquisador colaborador do Núcleo de Estudos de Gênero Pagu - Unicamp. ufscar7@gmail.com
}

cadernos pagu (37), julho-dezembro de 2011: 299-322. 
Frankenstein e o espectro do desejo

Frankenstein and the specter of desire

\begin{abstract}
Starting with the polemic about Frankenstein's (1818) authorship, I develop an analysis that includes it in a cultural history of subjectivity. The book is an example of the early gothic, probably the first book of science fiction, but it also takes part in a lineage of novels that explore the experience of being haunted by a phantom, a memory, a monster. I try to reconstitute that experience in historical and social psychological terms to comprehend the relations between desire, norms, and cultural conventions in the emergence of compulsory heterosexuality.
\end{abstract}

Key Words: Frankenstein, History of Subjectivity, Male Homosocial Desire, Compulsory Heterosexuality, Fear, Violence. 
Conta-se que na Suíça, em meados da década de 1810, um grupo de amigos que contava com Lord Byron e o casal Mary e Percy Shelley teve que ficar recluso por causa de um verão atípico, marcado pela erupção de um vulcão cujas cinzas tornaram os dias mais escuros e frios. Buscando distração, começaram a ler contos de terror alemães até decidirem criar um concurso sobre quem escreveria a história mais assustadora. Nascia Frankenstein, exemplar do romantismo e talvez o primeiro do gênero que denominariam mais tarde de ficção científica.

A primeira edição da obra foi publicada anonimamente em 1818, mas desde a segunda edição (1823), a autoria foi atribuída a Mary Shelley, filha da feminista Mary Wollstonecraft e do filósofo James Godwin. A jovem, cujos pais justificavam expectativas de genialidade, ainda por cima se casou com um dos maiores poetas de seu tempo, Percy Bysshe Shelley. Em uma época que poucas mulheres eram letradas e um número ainda menor se dedicava à literatura, sua origem e meio social privilegiados ajudam a compreender a criação de uma obra cujo impacto cultural foi tão amplo e duradouro.

Frankenstein é um sucesso literário dos mais adaptados para a esfera do entretenimento, tendo gerado peças de teatro, filmes de terror e até desenhos animados. A maioria dessas criações é sofrível e foca em versões simplistas do monstro que, nessas adaptações, herdou o nome de seu criador, eclipsando o protagonista do romance, o jovem cientista guiado pela ambição de criar um ser vivo.

Não é mero acaso que isso tenha se passado e Frankenstein, cujo subtítulo define como o moderno Prometeu, foi deixado em segundo plano nas adaptações, perdendo atenção para a sua criatura, a qual, na interpretação hegemônica do romance, seria a encarnação dos medos contemporâneos sobre as consequências do desenvolvimento da ciência. Temores que auxiliaram essas versões populares a transformarem a figura original do monstro um ser sofisticado que reflete sobre dilemas existenciais em francês - em um ser perigoso e irracional que se comunica por grunhidos. 
Frankenstein e o espectro do desejo

A despeito de sua popularidade, o romance não chegou a ser reconhecido como grande obra, injustiça contra a qual se voltou recentemente o historiador e polemista John Lauritsen. Em 2007, o pesquisador independente - e ativista gay de longa data publicou uma análise da obra com o título The man who wrote Frankenstein, na qual defende três teses: a de que o livro é uma grande obra da literatura inglesa, a de que foi escrito por Percy Shelley e não sua esposa e, por fim, que o romance tem como tema não reconhecido o amor entre homens.

A análise de Lauritsen se insere em uma profícua linhagem de polêmicas sobre o cânone literário inglês, assim como a criada por Oscar Wilde quando propôs que os Sonetos de Shakespeare tinham sido escritos para um rapaz por quem o escritor se apaixonara. Ou mesmo a discussão de Virginia Woolf do que teria se passado se Shakespeare tivesse tido uma irmã igualmente talentosa. Verdadeiras ou não, tais interpretações inseriram ruído e dúvida sobre obras $e$ autores que foram alçados ao topo da representatividade da nação e da própria cultura inglesa. Em suas diferentes formas de provocação, às versões hegemônicas, reside o feito dessas polêmicas para uma perspectiva cultural subalterna.

A obra de Lauritsen atraiu a crítica de feministas como Germaine Greer (2007) em uma excelente resenha na qual busca refutar todas as teses do historiador, realçando os componentes "femininos" da ansiedade sobre a "maternidade" de um filho que se revela monstruoso e assassino. Camille Paglia (2007), por sua vez, em um texto curtíssimo e pouco elaborado, concordou com sua tese da autoria masculina do livro. Qualquer que seja a posição, a favor ou contra, a polêmica se deu a partir da dúvida sobre se Frankenstein seria produto de uma escrita "feminista" ou "gay", tropo que pretendo refinar.

Certamente a edição de 1818 é um empreendimento literário $e$ intelectual respeitável ${ }^{1}$ e traduz ansiedades do século

\footnotetext{
1 As edições seguintes foram modificadas de forma a tornar o romance, dedicado ao pensador anarquista Godwin, mais aceitável para o grande público.
} 
que assistiu à aceleração da decadência da religião associada a um progressivo avanço da ciência. O livro apresenta a troca da gênese religiosa pela humana, quarenta anos antes da publicação de A Origem das Espécies (1859) de Charles Darwin, obra científica que substituiria de vez deus pela "natureza", inaugurando uma nova ontologia humana. Ao mesmo tempo, Frankenstein introduz incerteza tanto sobre o que motiva essa tomada do poder criativo para as mãos humanas quanto sobre suas consequências para o "cientista" e sua sociedade.

A obra é narrada em primeira pessoa por três vozes. Iniciase como uma carta do navegador inglês Walton em que conta para a irmã a ambição de alcançar o Polo Norte, assim como seu anseio de dividir sua conquista com a

companhia de um homem que simpatizasse comigo; cujos olhos respondessem aos meus. Você pode me chamar de romântico, minha irmã, mas eu amargamente sinto o desejo de um amigo (2004:20).

Em outra carta, anuncia que talvez tenha encontrado o "irmão de seu coração" (id.ib.:30) no rapaz que resgatara em seu navio - um jovem doente que seguia, em meio ao gelo, uma criatura desconhecida. Ao recuperar-se, Frankenstein tenta dissuadir Walton de suas esperanças devido ao seu malfadado destino, não sem afirmar que compreendia seu desejo porque já tivera tal amigo ansiado, mas o perdera para sempre.

Frankenstein toma a palavra e passa a narrar sua vida, desde a infância idílica na Suíça, marcada pela curiosidade científica precoce, até a sua partida para a universidade, na cidade alemã de Ingolstadt. A solidão e o sofrimento moldam seus estudos e a decisão de criar um ser. Frankenstein cria o monstro com partes de corpos abandonados, usados em autópsias,

Segundo Lauritsen, as modificações e cortes também retiraram componentes eróticos, sobretudo entre os personagens homens, do enredo original. 
Frankenstein e o espectro do desejo

frequentemente restos de pessoas marginais $e$, sobretudo, criminosos. Criado a partir de restos humanos, partes rejeitadas da própria sociedade, sua "feiúra" revela a expressão encarnada da abjeção, somatória disforme dos restos mortais de vidas desqualificadas e desprezadas. ${ }^{2}$ Segundo Francisco Ortega (2008), a partir do Murder Act de 1752, os corpos usados para dissecações foram os de condenados à morte, portanto o monstro une em si os socialmente culpados e que não conheceram perdão. ${ }^{3}$

$\mathrm{O}$ monstro descobre, por meio de sua rejeição, o que o romance apresenta como o principal problema da vida em sociedade: a intolerância e o preconceito. Daí, um dos pontos altos da obra ser o diálogo entre o jovem e sua criatura, momento em que o monstro toma a palavra e conta sua versão da história desde quando foi abandonado no laboratório e fugiu buscando esconderijo na floresta. Ali encontrou uma casa em que vivia uma família de refugiados políticos, em torno da qual passou a viver observando com admiração seu cotidiano $e$ aspirando crescentemente por compartilhar sua afeição e amizade. Suas esperanças se revelaram absurdas quando se apresentou à família $e$ foi maltratado e expulso, o que o tornou um ser amargurado $e$ assassino. O relato, sintomaticamente feito na língua de Rousseau, termina com o pedido desesperado de que Frankenstein crie para

${ }^{2}$ Em termos psicanalíticos, a abjeção descreve um sentimento de atração $e$ repulsa, o que faz parte de nós, mas que - recusado - causa temor e nojo a ponto de querermos nos distanciar e nos livrar dele/a. Não por acaso, os fluídos e as excreções - como o sangue, as lágrimas $e$ as fezes - são a mais óbvia materialização do abjeto em nós. Em termos sociais, elementos culturais como os monstros revelam o fascínio e o temor pelo que se aproxima e se distancia da imagem coerente que criamos de nós mesmos. Julia Kristeva e Mary Douglas são as principais criadoras da concepção corrente de abjeção, a qual tem se tornado mais popular, no presente, a partir de seu uso em estudos queer como os de Judith Butler.

${ }^{3}$ Ortega observa que essa lei foi substituída pelo Anatomy Act em 1832, o qual definia que os corpos usados nas dissecações seriam os dos pobres $e$ vagabundos, os que morriam em hospitais, asilos e instituições de caridade. 
ele uma parceira, com a qual embarcaria para as florestas da América do Sul.

O modelo de uma vida perfeita dentro dos padrões do casal heterossexual-reprodutivo seduz a criatura, mas não parece ter o mesmo apelo para seu criador. O pai de Frankenstein, que casara com a filha de seu mais querido amigo para salvá-la da pobreza $e$ do abandono, propõe ao jovem médico que aceite como esposa também motivado pelo compromisso e a solidariedade - sua irmã adotiva, Elizabeth. Essas relações motivadas por solidariedade entre um aristocrata e uma mulher dependente sugerem a frequência com que se forjavam casamentos de conveniência, os quais, como o romance insinua, se associavam a uma relação afetiva profunda com outro homem. As mulheres, portanto, viviam em uma condição terrível de dependência da (boa) vontade masculina para não serem relegadas à miséria e ao ostracismo moral, o que, mesmo evitado, ainda as mantinha reféns de alianças entre homens.

O jovem aceita a proposta de casar com Elizabeth, mas, aparentemente temendo a ameaça do monstro de que mataria sua futura mulher caso não criasse sua companheira, pede tempo ao pai para uma longa viagem com seu maior amigo desde a infância. Juntos em uma viagem que parece substituir a de núpcias, os inseparáveis Frankenstein e Clerval conhecem vários países e vão parar na Inglaterra, onde o cientista resolve realizar a promessa de criar uma parceira para o monstro. Atormentado pelas consequências incertas de sua criação, termina por destruir o laboratório atraindo a fúria de sua criatura na promessa de que mataria todos que ama.

Fugindo do laboratório em chamas, Frankenstein toma um barco e vai parar, inconsciente, em um vilarejo na costa da Irlanda. Tratado como um criminoso, descobre que haviam encontrado o corpo de um jovem. Ao se aproximar dele reconhece seu querido Clerval, cuja morte lhe é imputada. Preso e enviado para um hospício, depois de algum tempo, seu pai o resgata e o leva de volta à Suíça, onde é preparado o casamento 
Frankenstein e o espectro do desejo

com Elizabeth. Na noite de núpcias, enquanto busca se proteger do monstro, ouve um grito vindo do quarto, onde encontra, já sem vida, a esposa ainda em seu vestido de noiva. Pouco tempo depois, morre seu pai. Sem mais ninguém, Frankenstein decide procurar o monstro até o fim do mundo e o matar com as próprias mãos que o criaram.

O que, afinal, jaz por trás da fábula sobre o jovem cientista que consegue o impensável, criar um outro homem, mas é progressivamente atormentado e destruído por sua criação? A análise mais corrente vê no livro a necessidade de limites à ambição científica, enquanto Lauritsen afirma que Frankenstein é um romance psicológico de ideias,

sobretudo, uma alegoria moral sobre os efeitos malignos da intolerância e do preconceito, o ostracismo e a alienação, tanto das vítimas de intolerância quanto para a sociedade como um todo (2007:80)

Dessa forma, reconhece na obra um exemplar do gótico e esclarece o terror que assim o caracteriza:

Na época da vida de Shelley, homens e rapazes na Inglaterra eram enforcados por fazerem sexo um com o outro. A sexualidade entre homens não podia ser discutida aberta e racionalmente, mas obrigada ao silêncio: peccatum illud horribile inter christinos non nominandum [o pecado tão horrivel que não deve ser nomeado entre os cristãos]. (id.ib.:91)

Nesse contexto, nada menos surpreendente que o interesse amoroso entre homens constituísse uma ameaça social e gerasse ansiedade e medo naqueles que o sentiam. Sua análise de como a criação do monstro tem caráter erótico é corroborada pela forma como Frankenstein foge, tomado de pânico homossexual, quando vê a criatura ganhar vida. Fugindo do laboratório, o médico encontra inesperadamente seu amigo Clerval, o qual viera visitá-lo 
em Ingolstadt. Seu maior temor é o de que o amigo veja o "monstro", ou seja, tome conhecimento de seu desejo (id.ib.:101).

A atração de Frankenstein pela ciência é apresentada pelo historiador em seus contornos eróticos em uma relação tensa com as mulheres $e$ o feminino. Isso é perceptível no primeiro assassinato do monstro, o do menino William, irmão do médico, cuja morte é atribuída a uma jovem amiga de sua família que é, por fim, condenada injustamente à morte. ${ }^{4}$ Pouco depois desse episódio dramático, Frankenstein encontra o monstro no Mont Blanc, onde têm o diálogo central da história. O monstro demanda que seu criador compense seu abandono com a criação de uma parceira mulher, proposta diante da qual o médico titubeia.

A recusa de Frankenstein de criar uma parceira para a criatura provoca sua ira e a promessa de que matará todos que ele ama, o que - um por vez - se passa a começar pelo amado Clerval. A seguir, as mortes são dos que "prendiam" o jovem às convenções sociais. Nota-se o tom ameaçador e aterrorizante da ameaça do monstro: "I shall be with you on your wedding night" [Estarei com você em sua noite de núpcias]. O médico teme o "desejo fora do lugar", o que hoje compreendemos como homoerotismo, a assombrar sua primeira noite com a mulher que tomara como esposa. Lauritsen, quase no fim de sua análise, apresenta uma interpretação psicanalítica:

Muito bem, então, o que o monstro representa? A associação mais óbvia, para leitores contemporâneos, é com o Id freudiano (em alemão, das Es): uma coleção de memórias escondidas, desejos e pulsões primitivas que não são conhecidos para a mente consciente, o Ego (em alemão, das Ich). De acordo com a teoria freudiana, o ego

\footnotetext{
4 As análises que buscam paralelos entre o enredo do romance a vida de Mary Shelley costumam apontar o caráter biográfico dessa primeira morte, já que William era o nome de seu primeiro filho, que morreu na época de redação da obra.
} 
Frankenstein e o espectro do desejo

- policiado por sua consciência, o Super-Ego (em alemão, das Über-ich) - considera as pulsões do Id ameaçadoras e as reprime, portanto causando conflito psicológico.

Em termos freudianos, o monstro representa o Id de Victor Frankenstein: aspectos demoníacos e horrorosos de sua personalidade que seu Ego recusa reconhecer. E ainda, como duplo de Frankenstein, o monstro existe independentemente dele (a não ser que foi Frankenstein ele próprio, possuído por seu subconsciente monstruoso, que cometeu os assassinatos) (2007:161).

Lauritsen afirma que o monstro - feito de pedaços humanos - também representa muitas coisas em diferentes episódios, mas, em sua visão, em especial o elemento sexual no desejo entre homens. Coerente com análises históricas do período, como as de David M. Halperin e Alan Bray, aponta a forma de amor dominante no romance como a mais comum entre os homens da elite de então: a "amizade apaixonada". ${ }^{5}$ Lauritsen afirma que a amizade romântica era vivida como algo intenso e apaixonado que podia incluir ou não um componente sexual, mas, no romance em discussão, jamais se apresenta de forma explícita, antes como algo latente $e$ temeroso.

Frankenstein se revela um dos primeiros romances sobre subjetividade descentrada e, provavelmente, é o primeiro exemplar do gótico com a marca da paranoia homossexual, a qual encontraria seu estudo clássico apenas no início do século XX. A análise de Freud sobre o livro Memórias de um doente dos nervos (1903), a autobiografia do juiz Daniel Paul Schreber, compreende

5 Halperin (2002) volta-se contra a leitura mais comum de História da Sexualidade I: a vontade de saber de Michel Foucault, e afirma que há ao menos quatro tipos de relações amorosas e/ou sexuais entre homens encontradas em diferentes momentos históricos. Dentre elas, destaca a amizade ou amor masculino, a pederastia ou sodomia ativa, o "efeminamento" e a passividade ou inversão sexual. A homossexualidade, segundo ele, foi uma invenção psiquiátrica de fins do XIX que reinterpretou e rearranjou modelos de organização erótica anteriores. 
a paranoia como a manifestação neurótica ou mesmo psicótica do recalcamento do "componente homossexual" da sexualidade infantil que pode mais tarde se manifestar de forma reativa, ou seja, pelo sentimento de um homem ser perseguido ou estar sob domínio de outro. ${ }^{6}$

Eve Kosofsky Sedgwick, em seu clássico Between Men: English Literature and Male Homosocial Desire (1985), afirma que o gótico é um gênero literário que se desenvolveu lentamente até adquirir seus contornos mais conhecidos no período vitoriano. No gótico inicial, em que se insere Frankenstein, predominou uma compreensão aristocrática da homossexualidade masculina e a emergência de leitmotive como o terror do "indizível" e do "segredo" cujo conhecimento ameaça com algo trágico, possivelmente a própria morte. Sedgwick, por meio de suas análises de romances góticos, expõe a emergência histórica da paranoia homossexual, a qual apresenta como homofobia $e$ define como mecanismo psicossocial de controle da sociabilidade masculina e, ao mesmo tempo, do domínio dos homens sobre as mulheres. ${ }^{7}$

Em Frankenstein, a paranoia se vincula à figura do pai e sua maior demanda ao filho: a de que se case com sua irmã adotiva. A morte do pai não extingue a censura de Frankenstein ao seu desejo, antes cria um ponto de viragem na história: o médico deixa de ser o perseguido e passa a caçar o monstro, possível alegoria de seu inconsciente "monstruoso", socialmente recusado

6 Freud não analisou Schreber, mas sim sua autobiografia, na qual o juiz descreve seus delírios de emasculação, segundo os quais teria que se transformar em mulher para se unir a Deus. As relações entre Schreber e seu pai eram complicadas e delimitam a análise freudiana. Schreber pai reprimia sexualmente o filho a ponto de inventar mecanismos para impedir que ele se masturbasse durante o sono. Freud interpreta os delírios de perseguição do juiz como expressão de seus desejos homossexuais reprimidos pelo pai e pelo irmão. Outros, como Lacan e Deleuze e Guattari, criaram análises diversas sobre o conhecido "caso Schreber".

7 Apesar de listar Frankenstein entre os exemplares do gótico, curiosamente, Sedgwick não o analisa. 
Frankenstein e o espectro do desejo

e pessoalmente temido. Sintomaticamente, a morte do pai leva Frankenstein a trocar o medo de que descubram o monstro pelo desejo de eliminá-lo.

Quanto mais o romance avança, mais o criador se parece com sua criatura em sofrimento e melancolia. Sem o amigo, a família ou o pai, Frankenstein passa dois anos viajando à procura do monstro. A caçada justifica sua não fixação em uma vida convencional, mas mantém o médico sob o domínio de seu próprio segredo, o qual persegue, incansável, exaurido e já doente, até próximo do Polo Norte, onde é resgatado pelo navegante Walton.

A análise de Lauritsen termina sublinhando a necessária relação entre a autoria masculina do romance e a intolerância da época às relações amorosas entre homens, particularmente com relação ao seu elemento (homos)sexual. ${ }^{8}$ Sem refutar um vínculo importante entre experiência subjetiva e criação artística, mas atentando para a necessidade de historicizar as condições sociais dessas experiências, é possível reconhecer como Frankenstein retrata - e se origina - não exatamente da experiência homossexual, antes do temor social sobre os limites incertos das relações entre homens e suas consequências para as mulheres. ${ }^{9}$

Uma análise mais criteriosa em termos históricos exigiria levar a sério a definição que Michel Foucault fez da sexualidade como um dispositivo histórico do poder que emerge a partir do século XVII. Também exigiria lidar com o caráter social do desejo, o qual é criado e agenciado socialmente. Sedgwick, por exemplo,

\footnotetext{
8 A associação biográfica entre autoria e tema do amor entre homens é clara no argumento de Lauritsen de que Percy Shelley lera $O$ Banquete, de Platão, na época de criação do romance e o traduziu para o inglês no mesmo ano de publicação da obra (cf. Lauritsen, 2007:120)

9 A análise de Lauritsen tem claras limitações, sobretudo por transferir concepções contemporâneas do que é ser homossexual, para a época de redação do romance, dois séculos atrás e, também, por se apoiar unicamente na hipótese repressiva, ou seja, a de que a sexualidade seria reprimida socialmente. Para uma crítica da hipótese repressiva, consulte Foucault, 2005.
} 
foge de reducionismos totalizantes, que reduzem o social a um sistema sem dinamismos ou divergências, $e$ historiciza a constituição de um desejo homossexual por meio de uma cuidadosa releitura da obra do historiador Alan Bray. ${ }^{10}$ Ela explora como, no início do século XIX, as relações entre homens se davam em um enquadramento que define como de ambivalência coercitiva (coercive double bind): os laços com outros homens constituíam o cerne da vida social assim como o que mais evocava ansiedade devido à tênue distância entre estar com outro homem e se envolver sexualmente com ele. ${ }^{11}$

Sem querer resolver a polêmica sobre a "real" autoria do romance, que pode ter sido escrito por Mary, Percy ou mesmo pelo grupo de amigos, a seguir ensaio uma interpretação de Frankenstein como um romance que lida com as ansiedades sobre o papel do desejo para a coesão social. Em outras palavras, buscarei apresentar alguns apontamentos sobre a emergência de uma forma de terror cultural que, ao menos desde o século XIX, regula o desejo direcionando-o para relações com pessoas do sexo oposto, sancionadas pelo casamento e visando a reprodução.

No rastro do desejo

Frankenstein é uma das primeiras obras sobre o que hoje compreendemos como paranoia masculina ou pânico homossexual, a expressão subjetiva de forças sociais que operam a partir do medo intenso sobre uma possível conspiração contra seu bom funcionamento. Trata-se, portanto, de uma experiência pessoal causada pela exposição a mensagens sobre supostos perigos do desejo, o qual, desde quando passou a ser considerado

${ }^{10} \mathrm{O}$ historiador inglês Alan Bray (1982) explorou a emergência de uma experiência homossexual em fins do século XVII, a qual se tornou visível na sociabilidade masculina em molly houses e tavernas e em algumas reações sociais a ela.

${ }^{11}$ Sobretudo no magistral capítulo Toward the Gothic: terrorism and homossexual panic de Between Men, pp.83-96. 
Frankenstein e o espectro do desejo

socialmente relevante foi também confundido com a expressão de forças antissociais. ${ }^{12}$

Em inícios do século XIX, período em que as transformações econômicas, políticas e nos costumes se aceleraram como nunca antes na história, é compreensível que vigorasse um medo generalizado de "contaminação moral" devido à ampliação do contato entre as classes sociais. $\mathrm{O}$ contato mais temido era, sem dúvida, o erótico. A cruzada anti-masturbatória da segunda metade do século XVIII mostra a progressiva tentativa de controle do desejo nas classes altas, mas como controlar o que não tem direção certa ou objeto definido ${ }^{13}$

A perseguição à sexualidade infantil tinha como inimigo não declarado a fantasia sexual ou o que hoje compreendemos como desejo. O objetivo da crescente preocupação médica e pedagógica com a masturbação parecia ser o de retardar a sexualidade para a vida adulta, faixa etária em que - supostamente - as pessoas teriam aprendido a controlar o desejo, direcioná-lo para relações interpessoais dentro dos padrões coletivamente incentivados, os quais podem ser resumidos no modelo familiar-reprodutivo. Apenas a criação de uma forma astuciosa de controle baseada em uma ameaça constante pôde surtir efeito: um verdadeiro regime de terror em que o medo se revelou a forma mais eficiente de agenciamento do desejo. ${ }^{14}$

${ }^{12} \mathrm{O}$ estudo contemporâneo mais importante e influente sobre a relação entre o pânico homossexual e o que compreendemos como sociedade é a obra O Desejo Homossexual (2009) de Guy Hocquenghem, publicada originalmente no início da década de 1970.

${ }^{13}$ Foucault aborda a cruzada anti-masturbatória em seu curso Os Anormais (2001). Tal "cruzada" foi fundamental no processo de transformação da sexualidade de questão religiosa a assunto médico. Fato visível no famoso tratado sobre a masturbação de Tissot, publicado na Suíca em 1758. Sobre a questão, consulte a aula de 12 de março de 1975 (2001:335-369).

14 Já no século XX, essa gramática do terror adquiriu feições de pânicos sexuais como os que miraram na homossexualidade como ameaça à coletividade nos Estados Unidos da década de 1950 ou, de forma global, na epidemia de hiv-aids 
Apontar a emergência de um regime erótico marcado pelo terror não significa, de forma alguma, desvinculá-lo da esfera da violência, já que esta constitui um fenômeno muito mais amplo do que suas expressões físicas e seus usos apontam para objetivos diversos de domínio ou controle social. ${ }^{15}$ Nos últimos dois séculos, uma forma mais sofisticada e eficiente de controle social emergiu quando a violência deixou de ser aplicada direta e exemplarmente a alguns indivíduos e passou a constituir uma ameaça que todos devem evitar. Seu espectro é mais poderoso, por isso leva até mesmo ao terror, ao medo extremo advindo da possibilidade real de se tornar vítima. Isso é visível em diversos contextos históricos e relacionado a formas diversas de dominação social. ${ }^{16}$

No que se refere à ansiedade social com relação ao desejo homossocial masculino, Alan Bray (1982) buscou analisar historicamente a rejeição social às relações entre homens a partir de fins do século XVII. O pesquisador inglês termina surpreso por essas relações não terem gerado uma reação mais eficiente quer na perseguição aos locais de encontro ou mesmo por meio de maior número de locais de internação ou aprisionamento dos envolvidos. Sedgwick ressalta que a reação social à visibilidade dessas relações podia seguir, esquematicamente, três vias: a tentativa de erradicá-las (claramente impraticável), de suprimi-las

nas décadas de 1980 e 1990. Sobre esses pânicos sexuais, consulte Rubin, 1993 [1984].

${ }^{15}$ Autores como Norbert Elias (1994) e Michel Foucault (1998) mostraram como o suplício público, o castigo assistido pela comunidade, era parte da vida cotidiana europeia até o século XVIII. Basta evocar a tortura dos presos e o açoite dos escravos africanos, que na América se estendeu até a segunda metade do século XIX, para recordar como já vigorou e foi aceita a violência física hoje considerada crime e socialmente perseguida.

${ }^{16}$ Por exemplo, Sedgwick (1985) observa como o terror dos linchamentos no Sul dos Estados Unidos foi fundamental na manutenção de um regime de dominação racista até a década de 1960. Como uma espécie de terrorismo sancionado ou tolerado pelo Estado, ele estendia e tornava mais eficiente a dominação branca permitindo a exploração do trabalho e a manutenção da subcidadania dos negros. 
Frankenstein e o espectro do desejo

(o que seria contraprodutivo, pois poderia até fortalecê-las) ou sua regulação (relativamente efetiva). Historicamente, foi a terceira via a que se desenvolveu e que a teórica queer seguiu por meio da análise de romances góticos, fontes ricas para compreender ansiedades como o risco de sofrer violência pela transgressão de fronteiras sexuais. Nesse gênero literário, o terror se constrói pelo medo extremo da violência, frequentemente evocada por meio de um espectro, uma memória, um fantasma ou até mesmo um monstro.

Além de ser um exemplar do gótico, Frankenstein se insere em uma vertente de romances que lida com uma experiência pouco explorada nas ciências sociais, a de ser assombrado. Segundo a socióloga norte-americana Avery F. Gordon (2008), a literatura que lida com espectros constitui fonte quase inexplorada, mas cuja análise permitiria uma melhor compreensão da relação entre história, subjetividade e vida social. Para explorar essa interseção seria necessário romper criticamente com uma epistemologia que considera o empírico como apenas o material, o evidente e o real desenvolvendo uma sociologia mais atenta ao afetivo, ao cultural e à experiência. Gordon propõe investigar assuntos fantasmáticos (ghostly matters), fenômenos que assombram a vida social contemporânea como forças subversivas que foram reprimidas com maior ou menor violência: "A assombração é uma experiência assustadora. Ela sempre registra o dano infligido ou a perda mantida por uma violência social no passado ou no presente" (id.ib.:xvi).

Em sintonia com Sedgwick e Gordon, é possível ver no monstro que assombra Frankenstein uma espécie de fantasma corporificado, a versão antropomórfica de um conjunto de temores sociais de seu tempo. O fantasma é uma figura social de violência e dano, o que é mais evidente na criatura feita com partes dos corpos de condenados, os quais assombram os vivos com a demanda de reconhecimento das injustiças que lhes foram infligidas. 
Uma análise sociológica de Frankenstein poderia contribuir para o projeto de desenvolvimento de uma contra-história, na reconstituição daquilo que autores como Adorno, Horkheimer $e$ Marcuse definiram como alternativas históricas que assombram a sociedade estabelecida como forças e tendências subversivas. ${ }^{17} \mathrm{~A}$ possibilidade do rompimento de normas ou convenções culturais é reconhecível nessas forças sem nome ou materialidade documental, mas cuja existência moldou a constituição do que somos. ${ }^{18}$ No fundo, essa contra-história poderia ser melhor compreendida como uma contra-memória, na qual a fantasia $e$ o fantasmático não são desqualificados como superstição.

No caso de Frankenstein, escrito em meio à industrialização, urbanização e formação do modelo familiar nuclear que marcariam o que conhecemos como sociedade burguesa, o romance permite reconhecer a formação de um temor coletivo do rompimento com a tradição. Seu enredo - sem nomear ${ }^{19}$ - mostra eventos que configuram uma transgressão dos laços familiares, a recusa do casamento e uma forma inusitada de procriação.

A narrativa tem como fio condutor o medo que se cristaliza em terror em alguns episódios explicitamente violentos, os assassinatos de inocentes, de forma geral, a família estendida do

\footnotetext{
${ }^{17}$ Refiro-me aqui ao posfácio de Adorno e Horkheimer ao Dialética do Esclarecimento, publicado em inglês como On the Theory of Ghosts, assim como a algumas reflexões pontuais de Herbert Marcuse em $\mathrm{O}$ Homem Unidimensional.

${ }^{18}$ Uma história crítica das normas e convenções sociais exige atenção ao invisível, ao que não se manteve por meio de documentação oficial, conhecimento reconhecido ou materiais acessíveis, antes em ausências, formas alternativas de conhecimento e experiências não-reconhecidas.

${ }^{19} \mathrm{O}$ monstro não tem nome porque é algo que não pode pertencer ao reino do familiar e conhecido, mesmo porque o ameaça. A criatura é a materialização de um segredo de Frankenstein e o sucesso da narrativa reside na cumplicidade entre leitor e protagonista na manutenção desse segredo ou no temor de sua revelação. Até o fim, quando Walton observa o monstro lamentando a morte do criador, a criatura só é vista pelo jovem médico, por suas vítimas e por quem lê o romance, assim, sua existência vincula o destino trágico do cientista a quem se aventura a acompanhar sua história.
} 
Frankenstein e o espectro do desejo

protagonista. Criado em um período que o dispositivo de aliança se associava, não sem ambiguidades ou tensões, com o de sexualidade, o monstro vive ameaçando binários como visível/invisível, real/imaginário, vivo/morto, presente/passado e, assim, segue assombrando Frankenstein e quem acompanha sua história.

Ser assombrado equivale a entrar em um estado animado em que uma violência social reprimida ou irresolvida se faz conhecer, mesmo que de forma oblíqua. O caráter múltiplo do monstro, deste um constituído de muitos, lembra a ideia inicial de Freud sobre o inconsciente como um lugar onde todos os Outros vivem dentro de nós mesmos. Outros sociais, portanto, todos os condenados, marginais, excluídos ou reprimidos, os que cruzaram a linha da transgressão-subversão da ordem, dos valores ou da moral vigentes.

No século XVIII, portanto pouco antes da criação deste romance, Lynn Hunt (2009) explica como a compreensão do "humano" nasceu com os romances escritos por homens, mas com protagonistas femininas como Clarissa (1747-8), de Samuel Richardson, ou Júlia (1761), de Rousseau. Estes romances teriam, na visão da historiadora, criado a habilidade do público de se "identificar" com personagens fictícias em histórias sobre aspirações de autonomia. Em outras palavras, radicalizando o argumento da historiadora, estes livros escritos por homens teriam criado a subjetividade feminina como o próprio "humano".

No Romantismo, personagens homens como Werther foram capazes de causar empatia e até obsessão a despeito de viverem em desacordo com normas sociais. Frankenstein aparece em uma vertente já gótica e que inaugura certo "descentramento do sujeito" que renderia, em fins do século XIX, criações como Strange Case of Dr. Jekyll and Mr. Hyde (1886), de Robert Louis Stevenson. Enquanto em Frankenstein a subjetividade cindida aparece em dois personagens distintos, ainda que paralelos em 
seu caráter de criador e criatura, no romance de Stevenson, médico e monstro são duas faces da mesma mente. ${ }^{20}$

Se a subjetividade humana se constituiu como socialmente compreensível por meio dos romances de heroínas do século XVIII, é no seguinte que essa mesma subjetividade se apresentou cindida em obras com heróis masculinos atormentados. Talvez seja possível conciliar a análise dominante sobre o romance como uma crítica da ambição da ciência com esta que o insere em uma história da subjetividade, e Frankenstein possa ser compreendido como uma obra em que as esperanças na ciência são frustradas pela descoberta do inconsciente.

Assim, por meio de uma história dos romances, se forma uma compreensão da subjetividade humana, primeiro como feminina em seu desacordo com as normas e aspiração de autonomia e, mais tarde, como cindida em homens que vivem entre as obrigações racionais (sociais) e os desejos do inconsciente. Chegaríamos, portanto, a aventar a existência de um processo cultural ignorado de generificação da psique em que o ego tendeu a ser associado ao masculino e o Id ao feminino e, indo mais longe, a de um outro binarismo que se impôs na emergência de um saber especializado sobre a subjetividade.

$\mathrm{Na}$ visão de David M. Halperin (2002), a invenção da psicanálise se relaciona com o estabelecimento da homossexualidade como princípio da diferença sexual e social, o fundamento de uma compreensão da sexualidade fundada na individualização do desejo que, no século $\mathrm{XX}$, terminaria com a atribuição a cada indivíduo de uma orientação e identidade sexuais. Coerente com sua análise, o monstro de Frankenstein

\footnotetext{
${ }^{20}$ A obra de fins do século XIX já lida com o regime de controle da sexualidade entre homens que a aloca no segredo e que, no século $\mathrm{XX}$, seria denominado de "armário" (closet). Para uma análise do romance de Stevenson como alegoria da emergência do armário consulte o capítulo "O Armário do Dr. Jekyll" em Sexual Anarchy (1990) de Elaine Showalter. Sobre o armário, veja a obra de Sedgwick fundadora da Teoria Queer: Epistemology of the Closet (1990), cujo capítulo principal foi publicado em português no cadernos pagu (2007).
} 
Frankenstein e o espectro do desejo

precede $e$ auxilia a reflexão sobre um dos aspectos que comporiam uma futura compreensão da sexualidade humana como dividida em hetero ou homo.

Escrito em período muito anterior à emergência dessa divisão clara, que se inicia em 1870 e se conclui apenas no século XX com a consolidação da moderna identidade homossexual, ${ }^{21}$ Frankenstein se insere em um contexto cultural em que ainda vigorava um temor generalizado sobre os limites "seguros" nas relações entre homens. No início do XIX, o "perigo" de ultrapassar o permitido fazia parte da experiência subjetiva de todos os homens e, talvez, fosse até mesmo motivo de atenção ou suspeita por parte de mulheres. ${ }^{22}$

A emergente compreensão do desejo como a base da coesão social se associava a incertezas sobre sua natureza. Seria o desejo guiado pelo inconsciente ou pela razão? O que aconteceria se ele deixasse de ser regulado pela tradição, ou seja, o casamento e a constituição de família? O cientista cria um homem, portanto, transgride a expectativa da relação homem-mulher como necessária para a reprodução. Além disso, ao optar por dar vida a um homem adulto evoca as ansiedades coletivas sobre as consequências de um desejo sexual pelo mesmo sexo. ${ }^{23}$

\footnotetext{
${ }^{21}$ A criação do homossexual tem, como observou Jeffrey Weeks (1977:3-4), dois efeitos: "ajuda a fornecer um corte claro entre comportamento permitido $e$ proibido e, segundo, ajuda a segregar aqueles rotulados como 'desviantes' dos outros, assim contendo e limitando seu modelo de comportamento".

22 Estudos históricos recentes, como o de Chris Brickell (2006), apontam que, até fins do século XIX, ainda predominavam concepções de que a homossexualidade era algo "potencial" em todo homem, especialmente naqueles moralmente fracos, o que poderia levá-los a, nos termos da época, degenerarem. Para um estudo sobre essas ansiedades no contexto brasileiro de fins do XIX, consulte Miskolci e Balieiro, 2011.

${ }^{23}$ Fantasmas que, atualizados, continuam a rondar nosso presente e que, de forma cômica e iconoclasta, definiram uma das adaptações mais bem-sucedidas do romance, o musical britânico transformado em filme cult como Rocky Horror Picture Show (1975). Nele, um criminologista narra a história de um casal recémcasado que se perde e vai parar na mansão de Dr. Frank-N-Furter, o qual se
} 
No início do século XIX emergia o que hoje denominaríamos heterossexualidade compulsória, mas cujo caráter obrigatório se exprimia menos por uma norma claramente imposta, antes pela ameaça de punição de seu rompimento. Por isso o apelo quase universal do terror presente na obra e na forma como ela exemplifica como temores coletivos são subjetivamente incorporados. Provavelmente por isso, nas representações mais populares, o monstro toma a identidade de seu criador e ganha protagonismo, pois é o medo que ele evoca o verdadeiro fio condutor da narrativa. Segundo Donna Haraway (2009:96), "Os monstros sempre definiram, na imaginação ocidental, os limites da comunidade". Mas quais seriam os limites em Frankenstein?

A lista parece infinita. A começar pela transgressão do natural pelo humanamente inventado, há também indicações de que, entre os limites rompidos, há os de classe e raça, já que o monstro é criado a partir de órgãos de corpos de condenados à morte, em geral, pessoas das classes populares, além de almejar uma companheira com a qual seguiria para a América do Sul, área então compreendida como uma grande floresta habitada por povos bárbaros. Quer por origem ou destino, o monstro se insinua para fora do contexto aristocrático, "civilizado" e europeu, de seu criador.

O que unifica a lista acima é o vínculo do cientista com o monstro, ou melhor, a relação ambígua e contraditória de Frankenstein com seu desejo. Fugindo ou perseguindo o monstro, vive preso a ele, mas incapaz de se envolver e cuidar daqueles que

apresenta como "um doce travesti da Transilvânia transexual" que descobrira o segredo da vida criando Rocky Horror. O caráter sexualmente ambíguo e transgressor do cientista é revelador, assim como sua criatura encarna o homemfetiche do universo homossexual de fins do século XX. A popularidade do filme é corroborada por fatos como o de ser o mais antigo a se manter em exibição desde o lançamento, ter criado a sessão da meia-noite nos cinemas norteamericanos, além de atrair um número incontável de fãs em exibições comemorativas anuais em que o público encena a história. 
Frankenstein e o espectro do desejo

ama. ${ }^{24}$ A começar pela própria criatura que abandona após a criação, passando pelo irmão que é assassinado pelo monstro, pelo drama da jovem injustamente condenada à morte, a morte de seu maior amigo e de seus familiares. Frankenstein assiste a tudo sem conseguir impedir nenhuma das tragédias.

O cientista consegue apenas transformar seu temor paralisante, ou terror, em vontade de vingança. A partir da compreensão freudiana da paranoia, é possível dizer que essa inversão do desejo em temor se fundamenta em uma ação projetiva de conteúdos do inconsciente sobre o outro (eu te desejo = você me persegue). Essa ação pode-se qualificar como defesa do eu contra conteúdos inconscientes inconciliáveis (Id) com a representação que o eu faz de si. O que resiste à integração, no eu de Frankenstein, se volta, projetivamente, para o monstro: a encarnação de aspectos abjetos de seu criador.

Quer como criatura que persegue seus parentes e amigos, quer como a que decide perseguir até a destruição, Frankenstein lida com o monstro, sempre buscando se defender de aspectos não integráveis em sua auto-representação consciente. Passa de um temor-cúmplice da violência para a tentativa fracassada de transferi-la à sua criação, de forma que sua narrativa paranoica revela-se uma mescla tensa e aterrorizante de repressão sexual $e$ dano infligido a outros e a si mesmo. Coerente com a ansiedade sexual que caracteriza o gótico, a obra termina com uma afirmação da amizade apaixonada que moldava relações entre homens da aristocracia. Assim, mesmo recusando reciprocidade,

\footnotetext{
${ }^{24}$ Sobre essa incapacidade de se vincular emocional e afetivamente, vale destacar as observações de Sándor Ferenczi ("O homoerotismo: nosologia da homossexualidade", conferência realizada em 1911): "De fato, é surpreendente ver a que ponto se perdem nos homens de hoje o dom e a capacidade de ternura $e$ amabilidade recíprocas. Reinam abertamente em seu lugar, entre homens, a rudeza, o antagonismo e a rivalidade. Como é impensável que estes afetos ternos, ainda tão marcados na criança, tenham desaparecido sem deixar vestígios, cabe conceber estes sinais de resistência como formações reativas, como sintomas de uma defesa contra a ternura sentida por pessoa do seu próprio sexo." (1992:127)
} 
Frankenstein é amado e acolhido por Walton até morrer com sua mão entre as dele.

\section{Referências bibliográficas}

ADORNO, Theodor e HORKHEIMER, Max. Dialetic of Enlightment. New York, Continuum, 1987.

BRAY, Alan. Homosexuality in Renaissance England. London, Gay Men's Press, 1982.

BRICKELl, Chris. Sexology, the Homo/Hetero Binary, and the complexities of Male Sexual History. Sexualities, vol. 9, $n^{\circ}$ 4, London, Sage, 2006, pp.423-447.

FERENCZI, Sándor. O Homoerotismo: nosologia da homossexualidade masculina. In: FeRENCZI, Sándor. Obras Completas, vol. II. Rio de Janeiro, Martins Fontes, 1992, pp.117-134.

FouCAULT, Michel. História da Sexualidade I: a vontade de saber. Rio de Janeiro, Graal, 2005.

. Os Anormais. São Paulo, Martins Fontes, 2001.

. Vigiar e Punir. Petrópolis, Vozes, 1998.

GREER, Germaine. Yes, Frankenstein was written by Mary Shelley. It's obvious because the book is so bad. The Guardian, 09/04/2007 [http://www.guardian. co.uk/world/2007/apr/09/gender.books -acesso: 10/12/2010].

HALPeRIN, David M. How to do the history of homosexuality. Chicago, Chicago University Press, 2002.

HaRAWAY, Donna. Antropologia do Ciborgue: as vertigens do póshumano. Belo Horizonte, Autêntica, 2009.

Hocquenghem, Guy. El Deseo Homosexual. Madrid, Melusina, 2009.

Hunt, Lynn. A Invenção dos Direitos Humanos: uma história. São Paulo, Cia das Letras, 2009.

LAURITSEN, John. The Man who wrote Frankenstein: Percy Bysshe Shelley. New York, Pagan Press, 2007. 
Frankenstein e o espectro do desejo

MARCUSE, Herbert. A Ideologia da Sociedade Industrial. Rio de Janeiro, Zahar, 1964.

MISKOLCI, Richard e BALIEIRO, Fernando de Figueiredo. O Drama Público de Raul Pompeia: sexualidade e política no Brasil finissecular. Revista Brasileira de Ciências Sociais, vol. 26, no 75, São Paulo, ANPOCS, 2011, pp.73-88.

MISKOLCI, Richard. Pânicos Morais e Controle Social: reflexões sobre o casamento gay. cadernos pagu (28), Campinas-SP, Núcleo de Estudos de Gênero - Pagu/UNICAMP, 2007, pp.101-128.

ORTEGA, Francisco. O Corpo Incerto: corporeidade, tecnologias médicas e cultura contemporânea. Rio de Janeiro, Garamond, 2008.

PAGLIA, Camille. Resenha sem título. Salon.com 14/03/2007 [http://salon.com/opinion/paglia/2007/03/14/coulter].

Rubin, Gayle. Thinking Sex. In: ABELOVE, H. et alii. The Lesbian and Gay Studies Reader. New York, Routledge, 1992.

SCHREBER, Daniel Paul. Memórias de um doente dos nervos. Rio de Janeiro, Edições Graal, 1984.

SEDGWICK, Eve Kosofsky. A Epistemologia do Armário. cadernos pagu (28), Campinas-SP, Núcleo de Estudos de Gênero - Pagu/UNICAMP, 2007, pp.19-54.

California Press, 1990.

. Epistemology of the Closet. Los Angeles, University of - Between Men: Male Homosocial Desire and English Literature. New York, Columbia University Press, 1985.

SHELLEY, Mary. Frankenstein or The Modern Prometheus. London, Collector's Library, 2004.

SHOWALTER, Elaine. Sexual Anarchy: gender and culture at the fin-desiècle. New York, Penguin Books, 1990.

WeEKS, Jeffrey. Coming Out: Homosexual Politics in Britain from the Nineteenth Century to the Present. London, Quartet Books, 1977. 